\title{
Famotine Hydrochloride
}

National Cancer Institute

\section{Source}

National Cancer Institute. Famotine Hydrochloride. NCI Thesaurus. Code C77927.

A hydrochloride salt form of famotine, an isoquinoline antiviral agent with activity ag ainst myxoviruses and paramyxoviruses. 